IRA-International Journal of Applied Sciences ISSN 2455-4499; Vol.04, Issue 01 (2016)

Institute of Research Advances

http://research-advances.org/index.php/IRAJAS

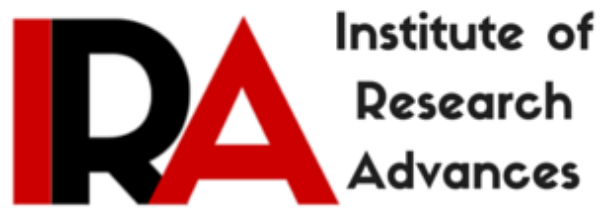

\title{
Effect of Gamma Radiations on the Quality and Shelf Life of Strawberry Fruit of the Uttrakhand Region
}

\author{
${ }^{1}$ Prianka Sharma \& ${ }^{2}$ Meetu Rastogi \\ ${ }^{\mathbf{1 , 2}}$ Maharaja Agrasen University, Baddi, Solan, India.
}

DOI: http://dx.doi.org/10.21013/jas.v4.n1.p3

\section{How to cite this paper:}

Sharma, P., \& Rastogi, M. (2016). Effect of Gamma Radiations on the Quality and Shelf Life of Strawberry Fruit of the Uttrakhand Region. IRA-International Journal of Applied Sciences (ISSN 2455-4499), 4(1). doi:http://dx.doi.org/10.21013/jas.v4.n1.p3

(C) Institute of Research Advances (cc) EY-NC

This works is licensed under a Creative Commons Attribution-Non Commercial 4.0 International License subject to proper citation to the publication source of the work.

Disclaimer: The scholarly papers as reviewed and published by the Institute of Research Advances (IRA) are the views and opinions of their respective authors and are not the views or opinions of the IRA. The IRA disclaims of any harm or loss caused due to the published content to any party. 


\section{ABSTRACT}

Present study was conducted to investigate the effect of gamma radiations on the quality and shelf life of strawberries. The aim of this study was to evaluate gamma radiation doses in range of 0.3- $1.5 \mathrm{kGy}$. The irradiated strawberries were stored in ambient (temperature $\left.25+-2^{\circ} \mathrm{C}, \mathrm{RH} 70 \%\right)$ and refrigerated $(3+-$ $I^{\circ} \mathrm{C}, \mathrm{RH} 80 \%$ ) conditions. In samples treated with dose 1.2-1.5 kGy no decay was recorded up to 9 days of ambient conditions. Under refrigerated conditions, strawberry samples of unirradiated and irradiated in the range of 0.3-0.9 kGy started decaying after 14 days of storage. No decay was observed in the samples treated with 1.2-1.5 kGy up to 28 days of refrigerated storage. Dose of $1.2 \mathrm{kGy}$ was significantly effective in reducing the weight loss and in maintaining the higher overall acceptability under both the storage conditions compared to the other treatments. This dose also proved effective in retention of significantly higher levels of total sugars compared to the other treatments. Thus, it was established that irradiating strawberries with dose of $1.2 \mathrm{kGy}$ can prove beneficial in facilitating the marketing of the fruit to distant places other than the local markets, thereby benefiting the growers.

Keywords: Ionizing Gamma Radiations, weight loss, decay percentage, overall acceptability (OAA), total sugars.

\section{INTRODUCTION}

Fruits are rich in carbohydrates, vitamins and minerals and poor in proteins, with $\mathrm{pH}$ values ranging from 7.0 to slightly acidic, and exhibit a characteristic higher water activity. These conditions make the produce suitable for the growth of several bacteria, yeasts and moulds. Thus, post harvest quality losses of fruits and vegetables during storage are global horticultural problems. Even mild bruising can contribute largely to the product's deterioration through enzymatic reaction and microbial contamination. Spoilage may be caused by a wide range of reactions such as physical, chemical, enzymatic and microbiological. The use of synthetic chemicals and fumigation to minimize such losses and to extend shelf life of fresh produce are primarily effective strategies, however they are vigilantly accepted by consumers because of potential health risks and environmental problems they pose.

Strawberry is a highly perishable fruit with maximum shelf life of around 3 days in ambient temperature $(25+-2 \mathrm{c})$ and 15 days in refrigerated temperature $\left(3+-1^{\circ} \mathrm{C}\right)$. It is highly vulnerable to post harvest decay due to its high respiration rate, environmental stresses and pathogenic attacks (Zhang et al, 2003). In fact, post -harvest decay of fruits and vegetables triggered by in-appropriate storage conditions, pathogenic attacks, mechanical injuries and environmental stresses are serious problems causing substantial losses of fresh produce every year (Zhang et al., 2011). The short storage life of the strawberry fruit makes its marketing a challenge. To facilitate the marketing to places other than the local market while maintaining the nutrient quality during storage requires effective post harvest treatments. Strawberries are one of the most difficult fruits to package and ship in a fresh state because of the rapidity with which it matures and breaks down. Until recently the only means available to prolong shelf life of this crop and permit shipment to distant markets with minimum loss of quality was refrigerated storage. This means, preservation can only postpone deterioration for a few days.

Different post harvest management techniques such as low temperature storage (Wiley, 1994) control atmosphere packaging (Holcroft and Kader, 1993, Wszelaki and Mitcham, 2003) surface treatment with synthetic chemicals (Geransayeh et al. , 2012) have been widely practiced. Controlled atmosphere packaging and low storage techniques are effective for shelf life extension of fresh commodities (Wiley, 1994) furthermore, there is an increasing demand from consumers to use pesticides free alternative methods to control post harvest decay of fruits and vegetables (Lichter et al.,2006)

Among the methods tested, gamma radiations has to be effective in reducing bacterial and mold contamination as well as delaying the ripening and senescence of fruits (Molins 2001; Fan et al, 2003). 
Gamma radiations are used as an alternative treatment for microbial disinfection (Hallman, 2008) and longevity of shelf life of fresh produce (Prakash et al; 2000). Irradiation has been recognized as an alternative to methyl bromide for treating fresh and dried agricultural products as a mode of decontamination, disinfection and improving nutritional attributes and shelf life (Mc Donald et al., 2012; Hong et al., 2008; Teets et al., 2008; Hallman 2000; Lacroix and Outtara 2000). Brasch and Huber also demonstrated the possibility of using ionizing radiations for preservation of food. Technical problems involved in irradiation sterilization of foods were reviewed by Hanna. Beraha et al demonstrated using gamma rays that there was a marked suppression of growth of several common decay organisms in infected fruits at doses that did not injure the fruit itself.

Previously several studies have been conducted on the efficiency of low doses of gamma radiation on post harvest ripening (Couture et al; 1990), decay (Silva et al., 2009) and on flavonoids of strawberry (Breitfellner et al., 2002) with beneficial and effective results. Furthermore, international and atomic energy association has recommended doses up to $3 \mathrm{KGy}$ of gamma irradiation associated with low temperature storage $\left(1-5^{\circ} \mathrm{C}\right)$ for extending shelf life and for delaying the growth of grey mould (Botrytis cinerea) and Rhizopus rot on strawberries and fresh produce (IAEA, 1994 ).

The literature survey indicates that there hardly seems any information available till this date regarding the radiation processing of strawberry varieties of Uttarakhand origin. Therefore present study was conducted to investigate the effect of gamma radiation on storage quality, shelf life extension and facilitating the marketing of fresh strawberries from Uttrakhand to distant places other than local markets. Because of the short shelf life of strawberries at room temperature most of the radiation studies conducted on strawberries stored under refrigeration. In the present study, fruits have been exposed to radiation doses of $0.3-1.5 \mathrm{kGy}$ in both the ambient and the refrigerated storage conditions. Then, the irradiated samples were studied for weight loss, percentage decay, overall acceptability and total sugars content under both the storage conditions.

\section{MATERIALS AND METHODS}

Strawberries weighing $500 \mathrm{gm}$ of uniform size and colour without any signs of fungal decay were procured from the strawberry orchards of Uttrakhand regions. Selection of fruit was done from the same orchard and fruit was harvested during morning hours. The harvested fruits were kept at $2^{0} \mathrm{C}$ in cold storage room.

The pre-cooled and packaged fruit was subjected to gamma doses in the range of 0.3-1.5 kGy using a irradiator having $\mathrm{Co}^{60}$ as gamma radiation unit .The experiment was performed at the Gamma Radiation unit at BAARC (Bhabha Atomic Research Center) in New Delhi. After irradiation, the samples were stored at ambient temperature $(25+-2 \mathrm{c})$ and refrigerated condition $\left(3+-1^{\circ} \mathrm{c}\right)$. The irradiated samples were evaluated after every 3 days in ambient condition and 7 days in refrigerated condition.

\subsection{Weight loss -}

Weight loss was calculated by the following formula as described by Akhtar et al (2010)

Weight loss $\%=(\mathrm{a}-\mathrm{b} / \mathrm{a}) * 100$

Where $\mathrm{a}$ and $\mathrm{b}$ represent initial and final weight respectively.

\subsection{Overall Acceptability (OAA) -}

Overall Acceptability of the fruit was judged by panel of 5 judges. The fruits were judged on the basis of color, texture and taste. For this, 4 point scale was used. $4=$ excellent, $3=$ good, $2=$ fair, $1=$ =oor. 
The samples were rated according to deep red colour, crisp texture and acceptable taste.

All the evaluation was carried out four times during study i.e. at day 0, 3,6 and 9 days after storage at ambient temperature and 7, 14, 21 and 28 days after storage at refrigerated condition.

\subsection{Total Sugars}

Total sugars as invert sugars were determined by modifying the method of Miller (1959) using 3, 5dinitrosalicyclic acid reagent (DNSA). In principle, the reducing sugars reduce DNSA to 3-amino-5nitrosalicyclic acid resulting in the formation of reddish-orange coloration that is measured spectrophotometrically at $540 \mathrm{~nm}$. A total of $5 \mathrm{ml}$ of filtered strawberry juice was mixed with equal amount of DNSA solution and incubated on boiling water bath for $10 \mathrm{~min}$. The mixture was allowed to cool at ambient temperatures and diluted further with double distilled water if required. The absorbance of the solution was measured at $540 \mathrm{~nm}$ using an ultraviolet visible spectrometer. Glucose solution of known concentration was used as standard for measuring the concentration of reducing sugars in the juice sample. The estimation of total sugars was performed following the inversion of sucrose (a non reducing sugar) to reduce sugar. To $15 \mathrm{ml}$ of strawberry juice, $1 \mathrm{~g}$ of citric acid was added and the mixture was incubated at $60^{\circ} \mathrm{C}$ for 20 to $30 \mathrm{~min}$ for complete inversion of sucrose to reducing sugars. The acid hydrolyzed solution was cooled to ambient temperature and neutralized by the addition of sodium hydroxide. From this hydrolyzed solution, a $5 \mathrm{ml}$ of sample was taken for quantifying total sugar in terms of invert sugar as per the method described above. Sucrose and total sugar concentrations in juice sample were calculated using the equations:

Sucrose $(\%)=($ Total invert sugar - Reducing sugar $) * 0.95$

\subsection{Decay Percentage:}

Percentage decay was calculated by visual observation of each sample as described by Zheng et al (2007). A fruit with visible brown spot and softened area was regarded as decayed and results were expressed as percentage of decayed fruits.

Decay percentage $=\mathrm{n} / \mathrm{N} * 100$

Where $\mathrm{N}=$ total number of fruits

$\mathrm{n}=$ number of decayed fruits

\section{RESULTS AND DISCUSSIONS}

\subsection{Weight Loss}

The Fig.3.1 indicated that weight loss was significantly higher in room temperature condition compared to refrigerated condition. It is revealed that after 3 days of ambient storage, there was no significant difference in weight loss between without irradiation and $0.3,0.6$ and $0.9 \mathrm{kGy}$ irradiated samples. However in case of refrigerated condition weight loss was significantly lower. After 7 days of refrigerated storage, weight loss was significantly higher in without irradiation samples. There was no significant difference in weight loss between $0.9,1.2$ and $1.5 \mathrm{kGy}$ irradiated samples. With increase in storage period, weight loss increased significantly in both the storage conditions; however, weight loss was significantly higher in unirradiated samples than irradiated samples throughout the entire storage period. Among irradiation treatments, dose of $1.2 \mathrm{kGy}$ was significantly effective in reducing the weight loss under both the storage conditions. Weight loss in fresh fruits and vegetables is mainly attributed to the loss of water caused by transpiration and respiration processes. The reduction in weight loss in strawberries treated 
with irradiation is because of the effect of the treatment on the respiration rate and in delaying the process of senescence (Hussain et al., 2010; Lester and Whitaker,1996).
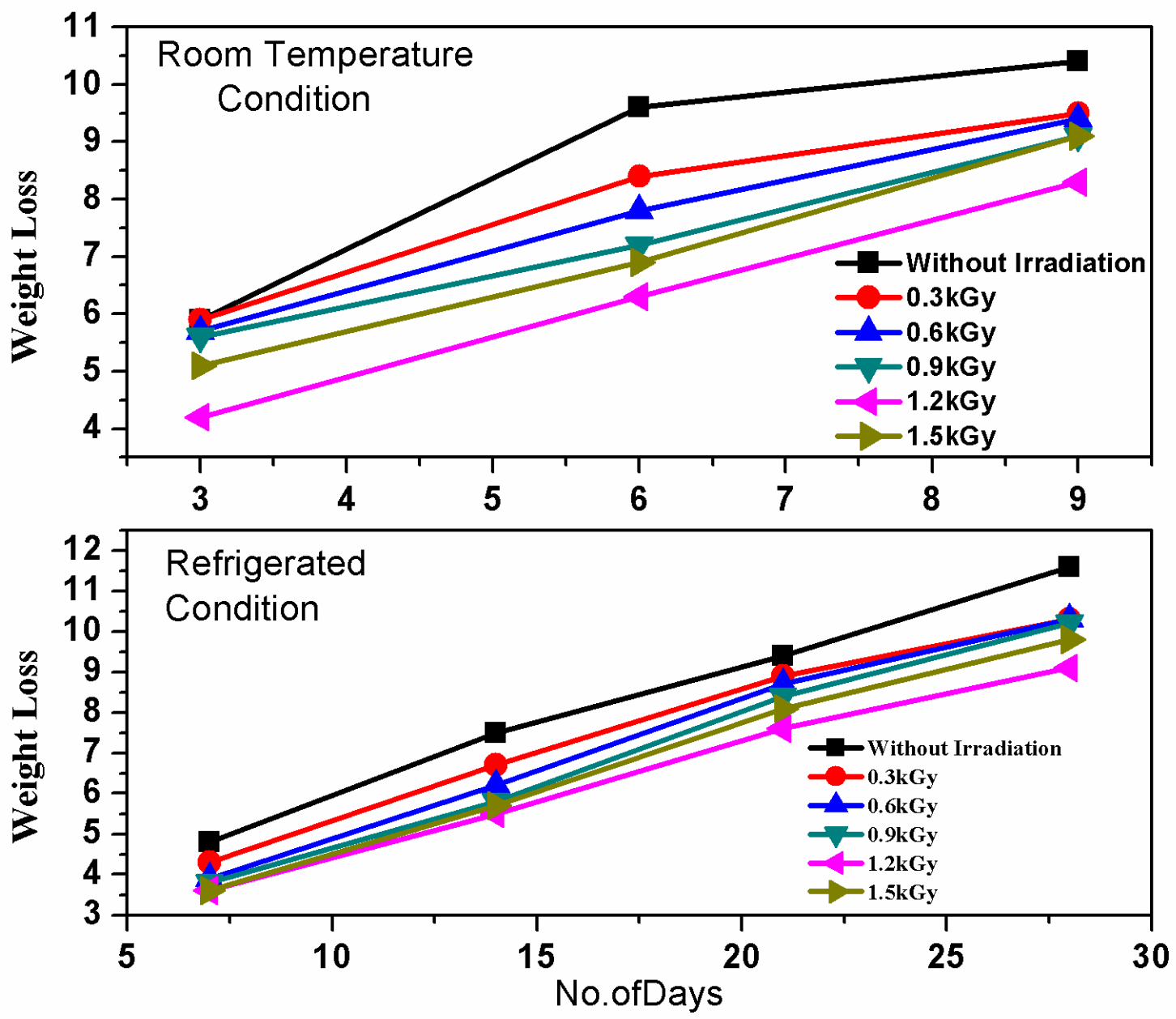

Fig. 3.1 Effect of gamma irradiation treatments on weight loss of strawberries during storage under ambient and refrigerated conditions.

\subsection{Overall Acceptability:-}

The Fig. 3.2 indicated that after 0 days of storage ( just after irradiation), there was no significant difference in overall acceptability of the strawberries under both the storage conditions. However as the storage period advanced, overall acceptability decreased under both the storage conditions but irradiated refrigerated samples were more acceptable even after longer storage period. After 3 days of ambient storage, overall acceptability of the strawberry samples though remained same for the unirradiated and low dose of $0.3 \mathrm{kGy}$ irradiation but it increased significantly after irradiation with $0.6,0.9,1.2$ and $1.5 \mathrm{kGy}$. In refrigerated condition, unirradiated and low dose irradiation did not effect much the overall acceptability up to 7 days but there was significant increase in overall acceptability for the samples irradiated with 1.2 and $1.5 \mathrm{kGy}$. For samples under refrigerated storage, overall acceptability after 21 days, was significantly higher in 1.2 and $1.5 \mathrm{kGy}$ irradiated samples compared to all other treatments and this trend was observed even after 28 days of storage. Dose of $1.2 \mathrm{kGy}$ proved to be effective in maintaining the higher overall acceptability under both the storage conditions compared to other treatments. The decrease in overall acceptability is related to the decrease in texture, color and loss of volatiles as 
perceived by the panelists because of rapid senescence and fungal decay. The effect of irradiation on inhibition of fungal growth and delaying the senescence proved significantly beneficial in maintain higher overall acceptability of treated strawberries compared with unirradiated samples during storage under both the conditions (Hussain et al.,2012).
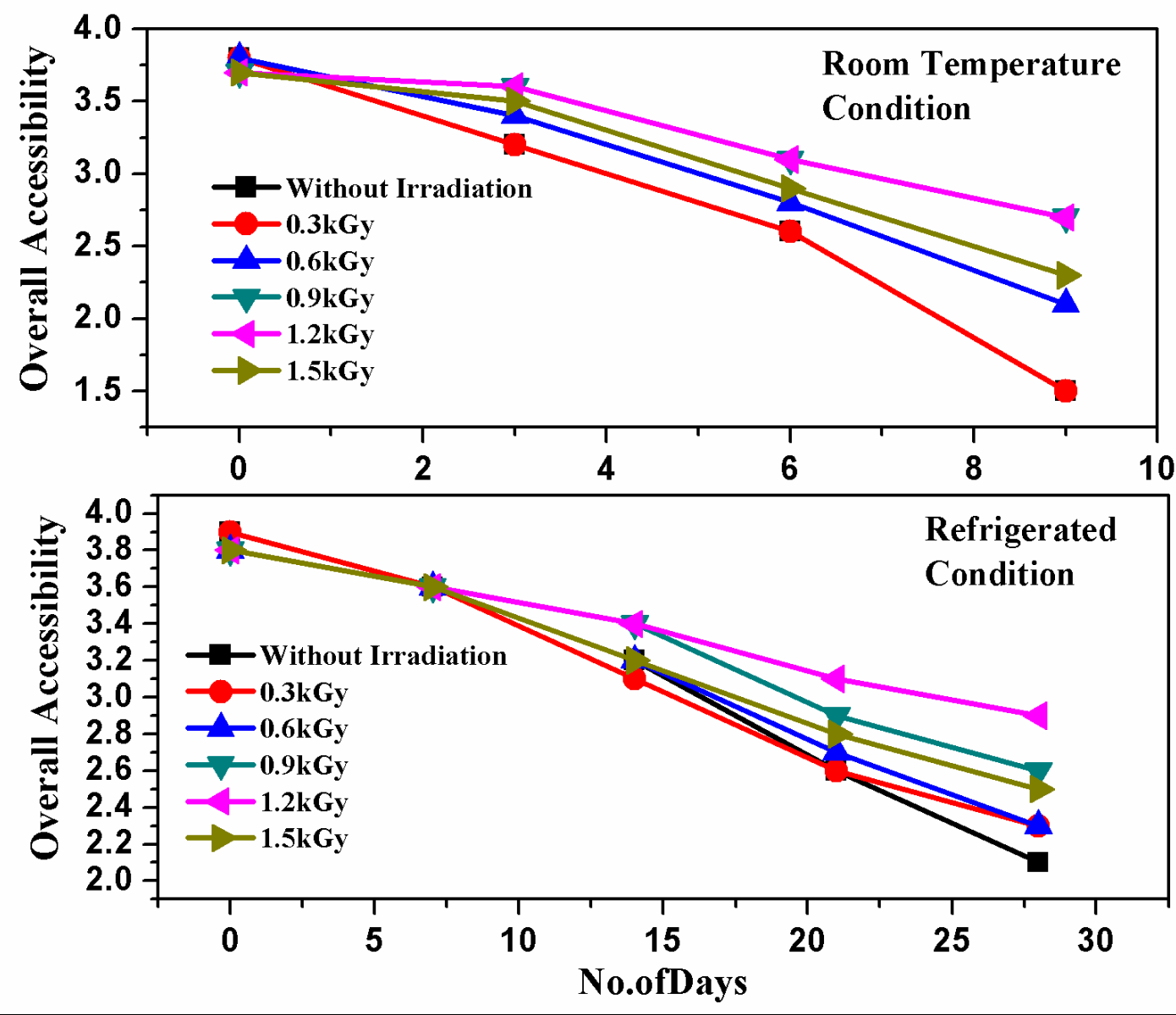

Fig. 3.2 Effect of gamma irradiation treatments on overall acceptibility of strawberries during storage under ambient and refrigerated conditions.

\subsection{Total Sugar:-}

Total sugars were significantly higher in refrigerated condition compared to ambient temperature condition. During storage, total sugars exhibited an increasing trend followed by a decrease in all the treatments under both the storage conditions. For both the conditions total sugars increased up to 3 days for ambient temperature condition and 14 days for refrigerated condition followed by a decrease. The increase in total sugars is attributed either to enzymatic conversion or radiation induced degradation of higher polysaccharides such as starches and pectins in to simple sugars, whereas the subsequent decrease is attributed to oxidation of sugars during respiration (Hussain et al., 2008). Towards the end of the storage, dose of $1.2 \mathrm{kGy}$ proved effective in retention of significantly higher levels of total sugars compared to other treatments under both the storage conditions. 

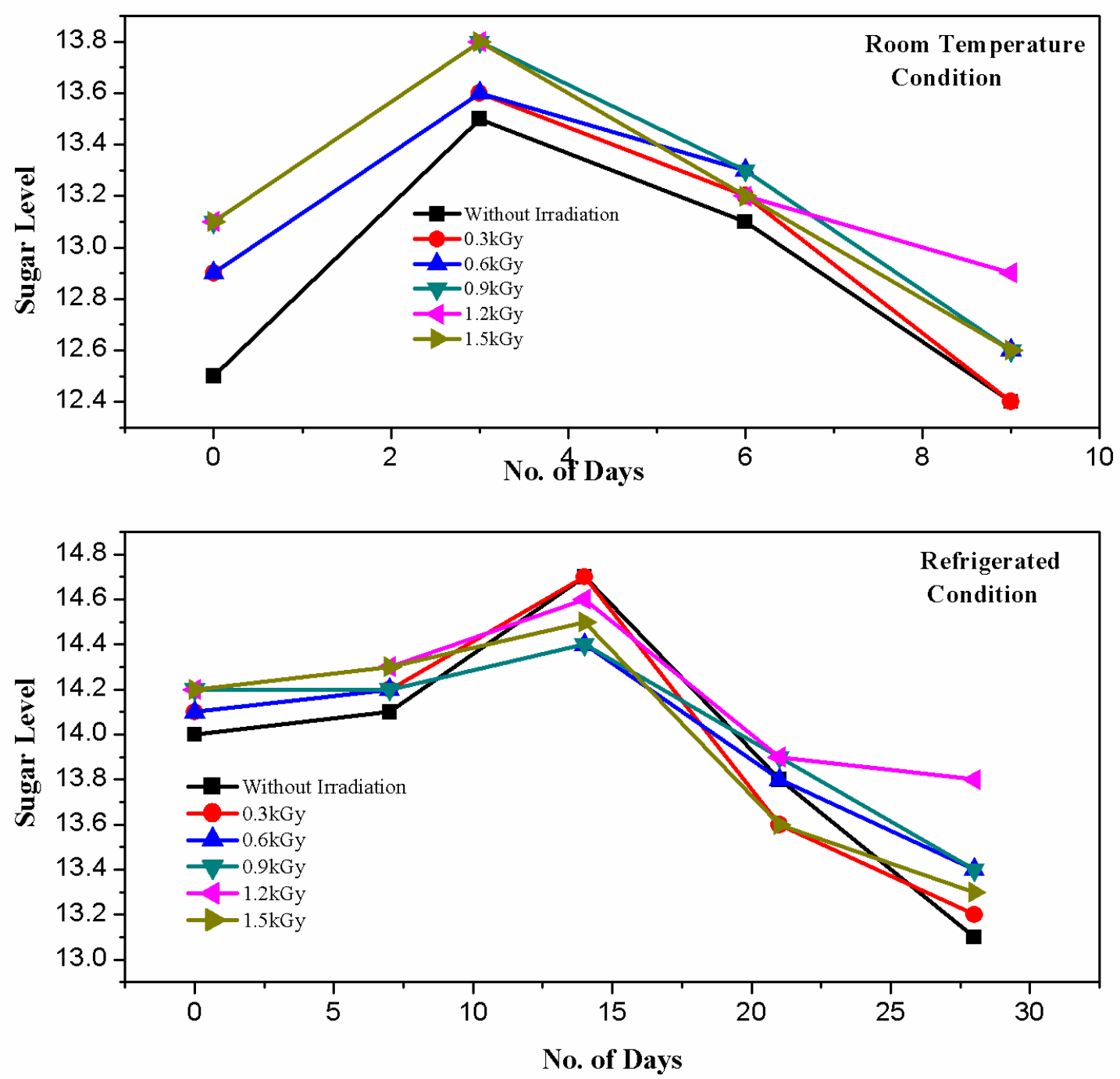

Fig. 3.3 Effect of gamma irradiation treatments on sugar level of strawberries during storage under ambient and refrigerated conditions.

\subsection{Decay Percentage:-}

Effect of gamma irradiation treatments on decay percentage of strawberries during storage under ambient, refrigerated and post-refrigerated storage conditions is shown in Fig.3.4-3.5. From Fig. 3.4, it is seen that under ambient conditions, unirradiated and irradiated with 0.3-0.6kGy samples started decaying after 3 days and were almost fully decayed after 10 days of storage. Samples irradiated with 0.9 kGy started decaying after 6days and were decayed to the extent of 39\% approx. No decay was observed in samples treated with $1.2 \& 1.5 \mathrm{kGy}$ up to 9 days of ambient storage. Under refrigerated conditions, un-irradiated and $0.3-0.6 \mathrm{kGy}$ irradiated samples started decaying after 14days of storage. Un-irradiated samples decayed up to an extent of $17+-2 \%$ while the decay percentage of irradiated samples is significantly low. For samples irradiated at $0.9 \mathrm{kGy}$ no decay was recorded up to 21 days of storage after that sample starts decaying. In samples treated with irradiation at $1.2 \& 1.5 \mathrm{kGy}$, no decay was observed even after 28 days of refrigerated storage. The samples were then taken out from the cold storage and kept under ambient conditions to monitor the further decay. Un-irradiated and $0.3 \mathrm{kGy}$ irradiated samples were fully decayed after 6 days of post refrigerated storage at $25+-2{ }^{\circ} \mathrm{C}$. For samples treated with $0.6-0.9 \mathrm{kGy}$ 
decay percentage is low as compared to un-rradiated and $0.3 \mathrm{kGy}$ treated samples. Even in the postrefrigerated storage condition, samples irradiated at $1.2 \& 1.5 \mathrm{kGy}$ shows no decay after 6 days.

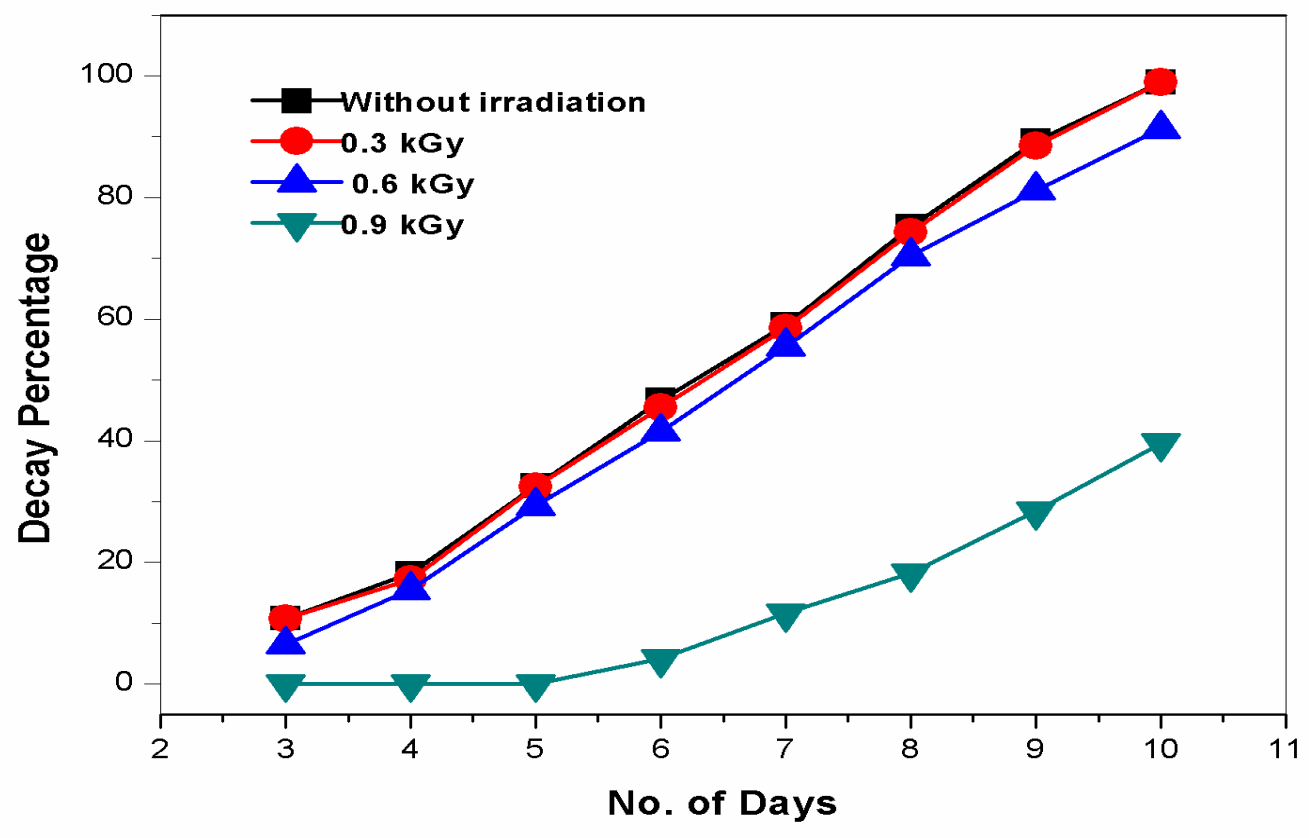

Fig. 3.4 Effect of gamma irradiation treatments on decay percentage of strawberries during storage under ambient condition. 

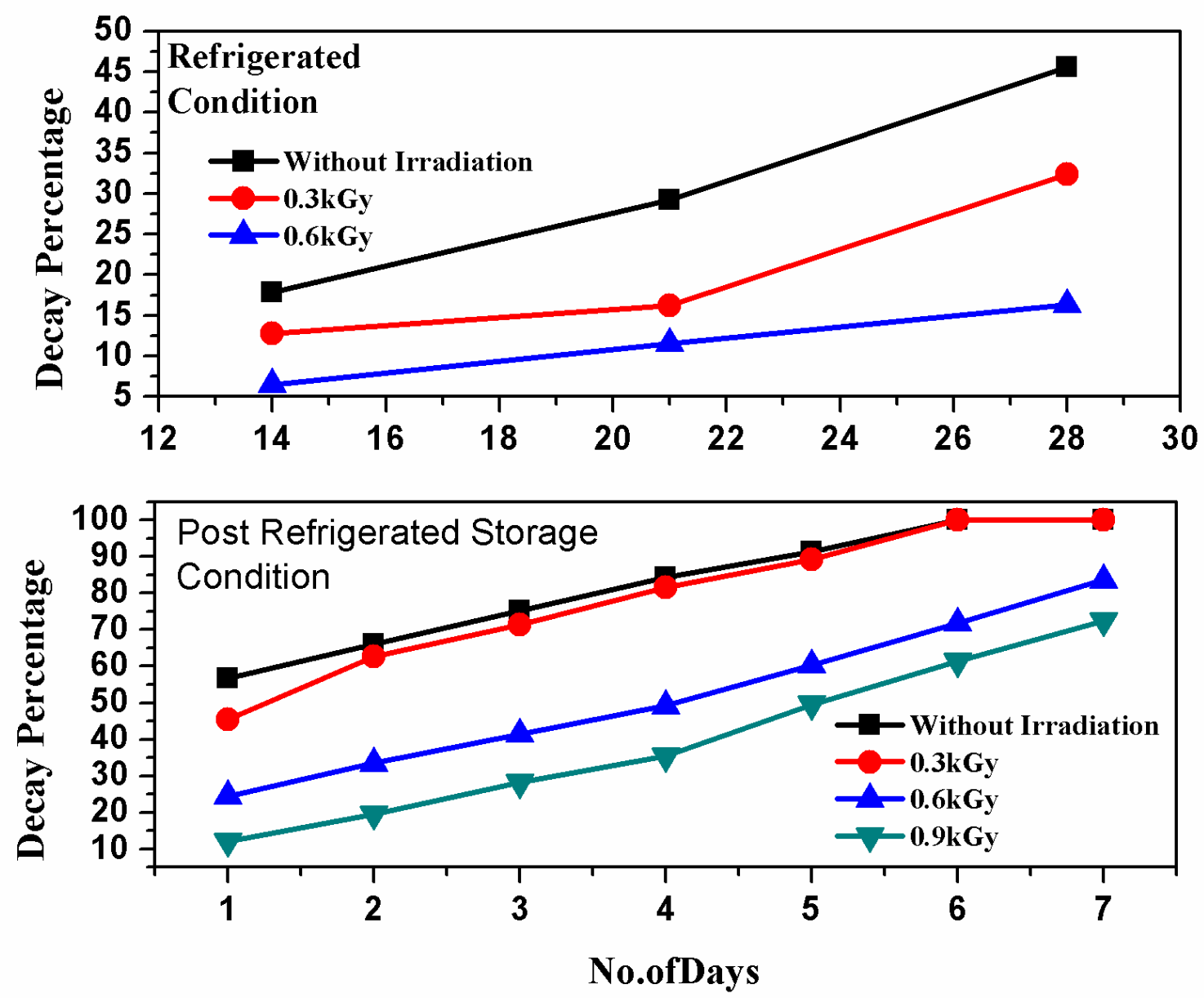

Fig. 3.5 Effect of gamma irradiation treatments on decay percentage of strawberries during storage under refrigerated and post-refrigerated conditions.

\section{CONCLUSIONS}

The investigations showed that gamma irradiation treatment of strawberries at doses 0.3 and $0.6 \mathrm{kGy}$ was not found effective with respect to delaying the fugal growth and shelf life extension. Radiation treatment of strawberries at 1.2 and $1.5 \mathrm{kGy}$ proved to be quite effective in maintaining the storage quality and significantly delaying the fungal decay of the strawberries under both the storage conditions. However, dose of $1.2 \mathrm{kGy}$ was found to be better compared to $1.5 \mathrm{kGy}$, as it maintained higher levels of total sugars, overall acceptability and lower levels of weight loss in strawberry fruits during storage under ambient as well as refrigerated conditions. Under ambient conditions, doses of 1.2 and $1.5 \mathrm{kGy}$ delayed the decaying of the strawberry fruits of both the varieties up to 9 days. Under refrigerated conditions, strawberry samples of un-irradiated and those irradiated in the range of $0.3-0.9 \mathrm{kGy}$ started decaying after 14 days of storage. No decay was observed in 1.2 and $1.5 \mathrm{kGy}$ samples up to 28 days of refrigerated storage. Thus, it was established that irradiating strawberries with dose of $1.2 \mathrm{kGy}$ can prove beneficial in facilitating the marketing of the fruit to distant places other than the local markets, thereby benefiting the growers. 


\section{REFERENCES}

Akhtar A., Abbasi N. A. and Hussain A. (2010). Effect of Calcium Chloride treatments on quality characteristics of loquot fruit during storage, Pak. J. Bot., 42 (1), 181-188.

Breitfellner F., Solar S. and Sontag G. (2002). Effect of gamma irradiation on falvonoids in strawberries, Eur. Food Res. Technol. 215, 28-31.

Couture R., Makhlouf J., Cheour F. and Willemot C. (1990). Production of $\mathrm{CO}_{2}$ and $\mathrm{C}_{2} \mathrm{H}_{4}$ after gamma irradiated of strawberry fruit, J. Food Quality, 13, 385-393.

Fan X., Niemira, B. A., Sokorai, K. J. B. (2003). Sebsorial, Nutritional and Microbiological quality of cilantro leaves as influenced by ionizing radiation and storage, Food Res Int., 36, 713-719

Geransayeh M., Mostofi Y. and Abdossi V. (2012). Effect of ozonated water on storage life and postharvest quality of Iranian table grape, J. Agric. Sci., 4(2), 31-38.

Lichter A., Gabler F. M. and Smilanick J. L. (2006). Control of spoilage in table grapes, Postharvest Rev., 6, 1-10.

Hallman G. (2000). Expanding radiation quarantine treatments beyond fruit flies, Agric Forest Entomol., 2, 85-95.

Holcroft D. M. and Kader A.A. (1999). Controlled atmosphere-induced changes in $\mathrm{pH}$ and organic acid metabolism may affect color of stored strawberry fruit, Postharvest Biol. Technol., 17, 19-32.

Hong Y. H., Park J. Y., Park J. H., Chung M. S., Kwon K. S. and Chung K. (2008). Inactivation of Enterobacter SakaZakii, Bacillus cereus and Salmonella typhi-murium in powdered weaning food by electron beam irradiation, Rad. Phy. Chem., 77, 1097-1100.

Hussain P. R., Meena R. S., Dar M. A., Wani A. M. (2010). Carboxymethyl cellulose coating and lowdose gamma irradiation improves storage quality and shelf life of pear, J. Food Sci., 586-596.

Hussain P. R., Dar M. A. and Wani A. M. (2012). Effect of edible coating and gamma irradiation on inhibition of mould growth and quality retention of strawberry during refrigerated condition, Int. J. Food Sci. Tech., 47, 2318-2324.

Hussain P. R., Dar M. A., Meena R. S., Mir A. M., Shafi F. and Wani A. M. (2008). Changes in quality of apple due to gamma irradiation and storage conditions, J. Food Sci. Technol., 45(1), 44-49.

IAEA (1994). Irradiation of strawberries- A compilation of technical data for its authorization and control., FAO/IAEA/WHOIAEA-TECDOC, pp.779:34.

Lacroix M., Ouattara B. (2000). Combined industrial processes with irradiation to assure innocuity and preservation of food products- A review, Food Res. Int., 33 , 719-724.

Lester G. E. and Whitaker B. D. (1996). Gamma ray induced changes in hypodermal mesocarp tissue membrane of pre and post storage muskmelon, Physiol. Plant , 98, 265-270.

McDonald H., McCulloch M., Caporaso F., Winborne I., Oubichon M., Rakovski C., Prakash A. (2012). Commercial scale irradiation for insect disinfestations preserves peach quality, Rad. Phy. Chem., 81, 697-704.

Molins R. A., (2001). Food Irradiation: Principles and Applications, $2^{\text {nd }}$ ed. Wiley Interscience. 
Prakash A., Manley J., Decosta S., Caporaso F., Foley D. M. (2002). The effect of gamma irradiation on the microbiological, physical and sensory qualities of diced tomatoes, Rad. Phy. Chem., 63, 387-390.

Silva J. M., Correia L. C. S. A., Moura N. P., Salgado P. L.. Maciel M. I. S. and Villar H. P. (2009). Sensorial analysis of strawberry submitted to the technology of ionizing radiation, Acta. Hort., 842, 863866.

Teets A. S., Sundaraman M., Were L. M. (2008). Electron beam irradiated almond skin powder inhibition of lipid oxidation in cooked salted ground chicken breast, Food Chem., 111, 934-941.

Wiley R. C. (1994). Minimally processed refrigerated fruits and vegetables, Chapman and Hall, New York, pp. 368.

Wszekaki A. L. and Mitcham E. J. (2003). Effect of combinations of hot water dips, biological control and controlled atmospheres for control of gray mold on harvested strawberries, Postharvest Biol. Technol., 27, 255-264.

Zhang M., Xiao G., Peng J. and Saloghe V.M. (2003). Effect of modified atmosphere package on preservation of strawberries, Int. Agrophysics, 17, 143-148.

Zhang H., Li R.and Liu W. (2011). Effects of chitin and its derivative chitosan on postharvest decay of fruits; A Review, Int. J. Mol. Sci. 12, 917-934.

Zheng Y., Wang S. Y., Wang C. Y. and Zheng W. (2007). Changes in strawberry phenolics, anthocyanins and antioxidant capacity in response to high oxygen treatments, LWT-Food Sci Technol., 40, 49-57. 